\title{
BMJ Open Development and psychometric testing of an instrument for measuring social participation of adolescents: study protocol of a prospective mixed- methods study
}

Tim Baerwalde, ${ }^{1}$ Britta Gebhard, ${ }^{2}$ Laura Hoffmann, ${ }^{2}$ Julia Roick, ${ }^{1}$ Olaf Martin, ${ }^{1}$ Anna-Lena Neurath, ${ }^{2}$ Astrid Fink ${ }^{1}$

To cite: Baerwalde T, Gebhard B, Hoffmann L, et al. Development and psychometric testing of an instrument for measuring social participation of adolescents: study protocol of a prospective mixedmethods study. BMJ Open 2019;9:e028529. doi:10.1136/ bmjopen-2018-028529

- Prepublication history for this paper is available online. To view these files, please visit the journal online (http://dx.doi. org/10.1136/bmjopen-2018028529 ).

Received 12 December 2018 Revised 27 December 2018 Accepted 4 January 2019

Check for updates

(C) Author(s) (or their employer(s)) 2019. Re-use permitted under CC BY-NC. No commercial re-use. See rights and permissions. Published by BMJ.

${ }^{1}$ Institute of Medical Sociology, Martin-Luther-University Halle-Wittenberg, Halle (Saale), Germany

${ }^{2}$ Department of Economics and Social Sciences, Hochschule Nordhausen, University of Applied Sciences, Nordhausen, Germany

Correspondence to

Dr Astrid Fink;

astrid.fink@medizin.uni-halle.de

\section{ABSTRACT}

Introduction Social participation is an important part of a young person's life. It influences the social experience, social-emotional development and dimensions of competence experience. This applies to people with or without physical disabilities or chronic diseases. Currently, there is no reliable assessment tool for measuring social participation of adolescents in Germany although social participation is a central goal of rehabilitation. The aim of this study is to develop, test and pilot an instrument that assesses social participation for adolescents between the ages of 12 and 17 years and to start a psychometric test.

Methods and analysis In a sequential mixed-methods study, adolescents with and without physical disabilities or chronic diseases are asked about their experiences with social participation as well as the individual significance of self-determination through semistructured interviews. The perspective of adolescents is supplemented by focus groups that will be conducted first with experts from social paediatric care and second with legal guardians. Based on this, an assessment instrument will be developed, evaluated and implemented in exemplary social paediatric centres (SPCs) and rehabilitation clinics and psychometrically tested in a pilot study.

Ethics and dissemination The study will be conducted in accordance with the principles of the revised Helsinki Declaration. The study was approved by the Ethics Review Committee at the Martin-Luther-University HalleWittenberg. The developed assessment instrument can be used in science to identify disadvantaged groups and to compensate for the disadvantages that could impair development. For this purpose, the results will be presented at scientific conferences and published in international peer-reviewed journals. In practice, the instrument can be used to determine the goals of rehabilitation together with the adolescents and to evaluate the achievement of these goals. For this, implementation workshops and further training will be organised and carried out in children's rehabilitation clinics and SPCs.

Trial registration number DRKS00014739; Pre-results.
Strengths and limitations of this study

- This mixed-method study will provide profound insights on the theoretical foundation of the term 'social participation' from the point of view of adolescents, legal guardians and experts.

- It will show the perspective of adolescents with and without physical disabilities and chronic diseases and, therefore, take several health dimensions into consideration to put a valid assessment tool into practice and research.

- Since this study follows the approach of providing an assessment tool to measure social participation in adolescents with or without physical disabilities or chronic illnesses, further research and development work is needed to measure social participation in mentally disabled adolescents.

\section{INTRODUCTION}

The introduction of the International Classification of Functioning, Disabilities and Health (ICF) by the WHO in $2001^{1}$ led to a change of paradigm in rehabilitative processes and welfare politics in Germany. Rehabilitative processes and welfare politics changed from the excluding care approach to an integrative process with preferably unlimited participation of people with disabilities and chronic diseases. ${ }^{2}$ The biopsychosocial model of the ICF plays an important role in rehabilitation for the recovery of significant improvement in functioning, especially at the level of activities and participation as well as in addressing changes in contextual and environmental factors/barriers, when the participation of a person is endangered or limited. ${ }^{3}$ The importance of participation as the goal of rehabilitative processes seems undisputed. ${ }^{4-7}$ The concept of social participation (in the following, only called participation) has 
increasingly become the focus of science and practice..$^{8-10}$ However, this poses a challenge for science and practice to develop and apply appropriate assessment tools and evaluation instruments. The German Law on strengthening the participation and self-determination of persons with disabilities (short form: Federal participation law) requires instruments based on the ICF for the assessment of individual needs. The instruments should be able to capture restrictions in activities and participation in different areas of life. Participation is particularly important for the development of adolescents. It affects the level of competence experience (eg, skills), social experience (eg, relationship experience) and social-emotional development (eg, self-efficacy, self-concept). ${ }^{11-13}$ However, especially for the adolescent group, there are no high-quality assessment tools available in Germany for measuring social participation. ${ }^{14}$ For the conception, development and the comparability of assessment tools, a transparent theoretical framework and a consistent understanding of terms are elementary requirements.

\section{The term of social participation}

In the ICF for Children and Youth (ICF-CY), participation is described as "involvement in a life situation" 15 which is affected through activities, personality of the adolescent (eg, motivation) and environmental factors (eg, family, environmental conditions, legislation).$^{16}$ Participation thus includes the social perspective of functioning. At the same time, activity is understood as the 'execution of a task or action by an individual'. ${ }^{15}$ Even though in the ICF and the ICF-CY, participation and activity are conceptually differentiated, they are ultimately summarised in one component, consisting of nine domains. ${ }^{14151718}$

In the distinction between participation and activity, there are different approaches in the literature. One presumption is that an activity primarily involves a functional aspect of an action that can be performed without a role performance at the societal level. ${ }^{4}$ Using 'a role performance at the societal level' as a distinguishing criterion should be analysed critically for adolescents with disabilities or chronic diseases because some activities such as food consumption frequently take place in interaction with others (eg, caregivers). The strict distinction of where an activity is primarily an individual activity is difficult to delineate. ${ }^{19}$ Another assumption to distinguish is the view on the complexity of the life situation. ${ }^{20}$ The hypothesis where participation differs from activity in terms of complexity seems reasonable ${ }^{20}$ but not distinct enough. It is therefore proposed to differentiate between a spatial (eg, school) and temporal (eg, recurrent daily) component. ${ }^{21}$ In addition to complexity, participation may also differ from activities by its meaning, and it may be understood as 'sets of organized sequences of activities directed towards a personally or socially meaningful goal'. ${ }^{21}$ Activities are therefore to be understood as smaller 'action units' out of which sequences of participation are designed. It is important that participation can be assigned to a rather higher-level goal of action. ${ }^{21}$
Even though four different qualifier options are proposed in the ICF-CY to differentiate between activity and participation, ${ }^{22}$ there has been no preference or homogeneity so far. ${ }^{17}$ Imms et al state that there are contemporary descriptions of how participation can be measured with the help of qualifiers, but in effect, it amounts to activity competence and not to participation. ${ }^{18}$

\section{Theoretical foundation of social participation}

In rehabilitation science, the concept of participation is predominantly determined by the ICF-CY. However, this raises the problem that the ICF-CY is based on the framework concept of the ICF and uses a mutual language, but the ICF itself emerged in a consensus procedure and lacks a theoretical foundation. ${ }^{23}$ Although the ICF-CY model is based on a biopsychosocial understanding of health, it is not sufficiently elaborated. Therefore, a theoretical inclusion of the concept of participation used here is relatively difficult.

Research suggests that participation is not only the number of activities a child participates in, or how often they attend that activity (attendance). Additionally, with regard to the feeling of involvement, prerequisites are observed, indicating it should be personally meaningful. ${ }^{724}$ Even if attendance and involvement are considered sets for the concept of participation, their relationship to each other is not yet completely clarified. ${ }^{18}$ To gain a more holistic view of the construct of participation in the ICF-CY, the introduction of a third qualifier of the subjective aspects of participation within the activity and participation domain is discussed. ${ }^{72425}$

Participation is considered as a 'multidimensional and evolving phenomena with the interaction of personal and environmental factors occurring over time'. ${ }^{7}$ It is seen as a process and as a result. For this reason, participation can be considered as both an independent and a dependent variable in research. ${ }^{9} 1018$

In recent research, Imms et al have presented a conceptual framework, the family of participation-related constructs, ${ }^{18}{ }^{26}$ which are closely related but not identical to participation. There are intrinsic person-related concepts that include activity competence, sense of self and preferences. These concepts influence future participation and are influenced by past and present participation. In addition, there are extrinsic environment-related concepts that influence and are influenced by participation. These factors should be distinguished between environment and context. Context is considered to 'be personal, considered from the perspective of the person participating, and relates to the people, place, activity, objects, and time in which participation is set' ${ }^{18}$ Whereas 'environment is external, and refers to the broader, objective social and physical structures in which we live. ${ }^{18}$ The processes of the interactions between these concepts and further distinctions can be found in Imms et $_{\text {al. }}{ }^{18}$

Overall, beyond the simple definition of the term participation in the ICF-CY, profound consideration is given to the theoretical foundation of the term, and the process 
of understanding participation must be continued in science.

\section{Measurement of participation}

Some reviews have been published on the analysis of participation assessment tools for children and adolescents. ${ }^{14} 1727-29$ In summary, although a large number of assessment instruments are available, an unqualified recommendation is difficult. ${ }^{1427}$ This is because many instruments mix items of activity and participation, ${ }^{14} 17$ no single instrument measures the whole extent of participation in all life areas, ${ }^{14} 28$ and the quality criteria (on content validity, internal consistency, reliability and construct validity) are not convincing. ${ }^{14} 29$

To date, three participation assessment tools have been translated into German language. ${ }^{30-32}$ Two of these instruments ('Participation and Environment Measure for Children and Youth',33 and 'Children and Adolescent Scale of Participation' $)^{32} 34$ are used as an external assessment in which legal guardians (parents or caregivers) assess the participation of the children or adolescent. This can lead to distortions, in particular due to the subjective components of participation (meaningfulness). The third and very often used instrument 'Children's Assessment of Participation and Enjoyment/Preferences for Activities of Children ${ }^{35}$ refers to leisure activities only, does not distinguish between participation and activity, and only reaches mediocre quality criteria. ${ }^{31}$ Due to the legal conditions, the German version is not available for scientific or practical use. As a consequence, there is no reliable and valid instrument for the self-assessment of the participation of adolescents in German-speaking countries.

\section{Aim of this study}

This study aims to close parts of the existing gap in participation measurement among adolescents in research and practice. Instruments for the assessment of participation should be used more often for the planning and evaluation of rehabilitation processes but are hardly available in German language. As part of a sequential mixed-methods study, a participation assessment instrument will be developed for questioning adolescents aged between 12 and 17 years.

\section{METHODS AND ANALYSIS \\ Study design}

The study is planned as a sequential mixed-method study. To understand the complex construct of participation and its multiple layers, a qualitative design is first required. Regarding the achievement of the goals outlined above, the exploratory approach in this study offers the opportunity to reconstruct the practice-related experiences and perspectives of the adolescents, their legal guardians (eg, parents) and interprofessional experts in the paediatric pathways of care. Subjectively perceived needs from the clinical practice can be explored to derive the requirements for an assessment tool. In terms of counteracting the phenomenon of cognitive dissonance reduction with its concomitant adaptive preference mechanism, meaning that goals are adapted to possibilities, the perspective of adolescents with and without disabilities or chronic diseases will be fully explored. ${ }^{36}$

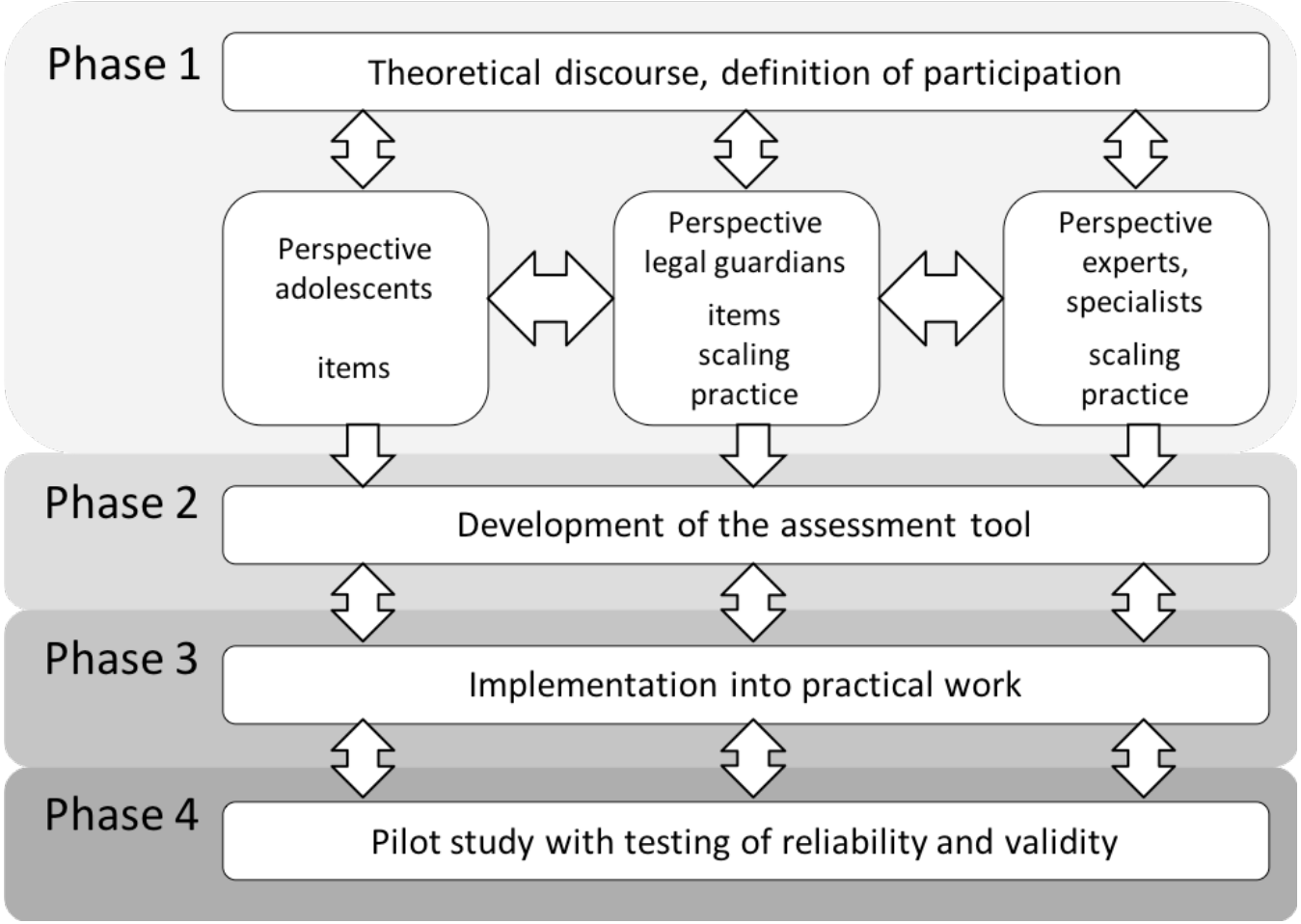

Figure 1 Study phases. 
The study will take place in four phases (figure 1). The first phase will contain data collection of semistructured interviews and focus groups. The analysis of the interviews will be followed by the development of a survey questionnaire which will be implemented and evaluated in a pilot study as well as checked psychometrically in this last phase.

Recruitment into the trial will start in February 2019, and the study is due to finish by October 2021.

\section{Patient and public involvement}

Some years ago, the two principle investigators (AF and BG) worked with existing assessment instruments to record social participation. ${ }^{1431}$ By working with the participants, they identified the limitations of the existing instruments and identified the need to develop a new instrument. This finding is based, besides the literature, on the priorities, experiences and preferences of the participants at that time and led to the developed question. The study design is a classic design for the development of new assessment instruments. The principles of good scientific practice were the guiding principles. The target group of the study (young people between the ages of 12 and 17 years) was not included in the development of the design. The open approach of the qualitative part of the study offers opportunities for adaptation based on the participants' preferences and experiences in recruitment and conduction of the study. As the instrument is more intended to support practice and research, the interest of individual participants may be relatively low. However, since participation in research may be an exciting experience for young people and their legal guardians, ways of reflecting results are being prepared. The results of the study will be sent to the participants individually on request, in addition the settings of the participants (schools, social paediatric centres (SPCs), etc) will be informed and, if desired, information events on the results will be arranged. The results will be published in scientific journals. It is also planned to distribute the results and the final version of the instrument, for example, to rehabilitation centres and SPCs for free.

\section{Study population/recruitment}

Participating adolescents with physical disabilities or chronic diseases will be recruited via the education centre for pupils with special needs and the SPC in Halle (Saale), Germany. For the recruitment of non-disabled adolescents, four schools (two in urban regions and two in rural regions) will be approached in order to recruit interview partners. As part of the recruitment of adolescents, legal guardians should be engaged as well as participate in focus groups.

The individual interviews will include adolescents between the ages of 12 and 17 years, both with and without disabilities or chronic diseases in the area of physical and motor development. The interviews will only be conducted when a written consent is available. According to the theoretical sampling, ${ }^{37}$ the cases will not be determined at the beginning of the research, but will be successively recruited in the alternation of collection and development of theoretical categories, with a following further collection. Depending on the level of the category, it will be decided whether a participant from the urban or rural region is interviewed or whether an adolescent with or without disabilities or chronic diseases is interviewed. The recruitment will continue until a theoretical saturation is reached. Experience from our own and other studies indicate leading approximately 40 interviews, 20 with adolescents with disabilities or chronic diseases and 20 with adolescents without disabilities or chronic diseases. ${ }^{38}$ Adolescents with acute illnesses, with complex cognitive impairments or without written consent are excluded. The ability to communicate by voice must be given.

The national experts for participation are recruited via the 'European Association on Early Childhood Intervention'. Hereby, extensive contacts can be made with different SPCs and various rehabilitation facilities. The constellation of the focus groups allows us to generate heterogeneous groups, who work out different experiences and impressions in their discussions. A group size of six to eight participants has been proven to be a good group size in focus group discussions with experts. ${ }^{39}$ The relevant target group will be better reached by a specific approach rather than by random selection. The selection strives for a group dynamic which is considered to be beneficial for the research objective of clarifying the basic understanding of the term (participation), the understanding of the theoretical construct of social participation of adolescents as well as the addition of the perspective of the adolescents. The participants of the first phase will be informed about the second phase of the study. At the same time, the willingness to participate in the second phase of the study (giving feedback to an assessment tool) will be enquired.

\section{Study phase 1: Theoretical discourse \\ Collecting data of adolescents}

Since the theoretical background and the development of the category system require detailed knowledge of a person (eg, the kind of disability) and their situation (eg, place of residence), extensive and detailed interviews are conducted which consider the individual circumstances and provide enough time for the participant. ${ }^{40}$ Semistructured in-depth interviews will be conducted, which can take place at the Institute of Medical Sociology, the SPC, at schools or at the home of the participants, with the participants choosing the place themselves. Topic guides will be developed for the interviews, which contain open questions and offer areas of discussion that are addressed in the interviews (without specification of a certain order). The interviews will last a maximum of $60 \mathrm{~min}$ and are audio-recorded with the consent of the participant and completely transcribed afterwards. The literature shows that interviews can be carried out from the age of 7 years. ${ }^{41} 42$ Since the interviews are planned 
with adolescents from the age of 12 years in this research context, the age-related challenge can be put into perspective because adolescents at this age are able to have open conversations, both interactively and cognitively as well as verbally. Nevertheless, during the entire research process, the interviews must be individually adapted to each adolescent and their individual preconditions. Moreover, the interview guidance of the researcher must be performed flexibly and carried out preferably by experienced qualitative interviewers to stimulate narration among shy or reluctant adolescents. For the present study, it is very important to understand everyday living from the adolescent's point of view because, especially in regard to opinions, attitudes and the behaviour of adolescents, interviews with proxies (eg, interviews with parents or a legal guardian) are insufficient. ${ }^{42}$

To follow the scientific understanding of grounded theory, data collection, preliminary evaluation and theoretical sampling take place in a reflexive process. ${ }^{37}$ This procedure is complemented by theory-oriented coding, constant comparison and writing of memos throughout the data collection process and beyond.

\section{Preparation and development of a topic guide}

Semistructured topic guides that are developed for individual interviews contain open questions and provide conversational topics for the talk that are thematised without predetermining an order. ${ }^{43}$ This allows the most open conversation technique on sensitive topics. Taking the conversation dynamics into account, the key questions in the research process are modified, revised and adapted, and dependent on the study participant. ${ }^{40}$ Despite predetermined problem dimensions, the key questions are designed as open as possible in order to provide the participants with sufficient space for their representations, descriptions and arguments. The topic guide is based on existing evidence and aims to extend previous knowledge. It will be subjected to a pretest.

\section{Analysis of the interviews with adolescents}

The audio-recorded interviews are transcribed and analysed according to grounded theory ${ }^{37}$ using MAXQDA software: In the first phase of the 'open coding', short, incisive and comparatively abstract concepts (codes) are developed, which characterise the content of the particular text passage. The second step of the analysis, 'axial coding', examines certain categories more intensively by evaluating relationships between this category and other categories or subcategories. The 'selective coding', as the third analysis step, focuses on the key categories and prepares the final theory formation. On the other hand, relationships and interactions between topics are examined. ${ }^{37}$ The category scheme is being built up parallel to the field phase. The collaborative coding is performed by research associates, with a continuous exchange with principal investigators; additionally, a presentation of the categories and interpretations in the joint working group 'Qualitative Methods' at the Institute for Medical Sociology is anticipated.

\section{Data collection with the experts and legal guardians}

In the data collection with the experts and the legal guardians, we will use focus group discussions because it is a resource-saving method for data collection. ${ }^{39}$ With that, we complete the perspective of the adolescents with regard to the perspective of legal guardians (three groups) and experts (three groups). The focus group is also well suited for hypothesis generation ${ }^{44}$ and development of the questionnaire. ${ }^{45}$

In this study, expert opinions are important because the adolescents and their legal guardians can only assess the current situation; however, the experience of how the disabilities or chronic diseases may develop is the perspective of the experts and practitioners. From a methodological point of view, it is important that respondents are equally or similarly affected by the topic or have expertise on the topic or issue. The individuals themselves are not the focus, but the thematic statements or communications within the interviewed group are. It is important that the dynamics of the arising group discussions are explicitly included in the analyses because the importance of the interaction, discourse and group processes for the composition of opinions and the orientation and meaning of the patterns is essential in this phase. ${ }^{39}$

The topic introductions for the focus groups of the legal guardians are based on the guideline for the qualitative interviews but are discussed from the perspective of those who are secondarily affected. Furthermore, aspects from the individual interviews of the adolescents should be included in the focus groups of the legal guardians. The discussions in the focus groups are recorded via video technology for in-depth analysis and evaluation.

\section{Analysis of the focus groups with experts and legal guardians}

The results of the focus groups will be compared and supplemented with the current state of discussions of international literature on the examination of the theoretical construct of participation. Therefore, the analysis of the focus groups is based on the qualitative thematic analysis according to Boyatzis. ${ }^{46}$ At the beginning, the analysis will be based on thematically related passages of description. First, a category system is developed out of the discussion guide, with the help of which the material is 'dismantled' (deductive evaluation strategy). In the following inductive step, new categories are developed. For this purpose, individual statements are elaborated and compared through summary, explication and structuring. Finally, the results are compiled, interpretations are worked out and generalisable statements are determined. These are brought together with the insights of the data collections with adolescents and the legal guardians. For the documentation and evaluation of the data, the software MAXQDA is used. 


\section{Phase 2: Development of an assessment tool}

The development of the participation assessment instrument takes place in three steps: item generation, qualitative review and cognitive pretest. The collection of items and required response scales are based on the findings of the qualitative study, as well as previous theoretical considerations and existing instruments. For the item development, the categories that are being queried from the interviews are determined. Then, a determination is made regarding interview results that may have already been adequately mapped by existing items in other questionnaires. The results of the analysis of the focus groups are included in the item generation. In addition, the expert opinion regarding the scaling and dimensioning to be made for the practice is incorporated into the instrument. Subsequently, questions are constructed for aspects for which there are no suitable items so far. In the following, the items and response scales are determined methodically. The items are based as close as possible on the quotes from the interviews to reflect the description, the quotes and the language used by the group of adolescents. A preliminary version of the questionnaire will be prepared.

In a second step, experts (corresponding to the focus groups) and persons affected (adolescents and their legal guardians) are asked to review the instrument, fill out a questionnaire and send it back to the researchers. The unambiguousness of the item description, explanation of the possible answers as well as the content-related fit, completeness and missing overlaps are in the foreground. Based on the feedback, a revision will be made and the version developed here will be included in the cognitive pretest. This third step is carried out with young people of the target group as a 'Think Aloud'. ${ }^{47}$ In this case, people who are filling out the questionnaire are asked to think out loud and to verbalise their thoughts that lead them to the answer. ${ }^{47}$ With this procedure, hints can be obtained once again on the most different question problems. The 'Think Aloud' is audio-recorded, additionally recorded in writing and evaluated by means of the thematic analysis according to Boyatzis. ${ }^{46}$

The pretested and revised questionnaire will be transferred into the third phase (implementation).

\section{Phase 3: Implementation into the practical work}

As part of the study, the newly developed questionnaire will be implemented in two practice areas (SPC and Rehabilitation Clinic for Adolescents). The implementation is carried out with workshops in the facilities in order to determine the correct usage of the questionnaire. ${ }^{48}$ As part of these workshops, the first results of the study are presented. The practical implications are discussed with the participants (doctors, psychologists, physiotherapists, occupational therapists) and the questionnaires and their usage will be presented.

\section{Phase 4: Pilot study with testing of reliability and validity}

In the pilot study, the questionnaire will be tested in the designated field such as the SPC or rehabilitation clinics as well as with non-disabled adolescents. For adolescents without physical disabilities or chronic diseases, schools will be used for access to the adolescents.

For the clinical sample, the staff of the facilities will hand the questionnaire to adolescents in the facility where they can answer it promptly. The experts in the practice are interviewed with a short questionnaire regarding the handling of the assessment as well as the utilisation of the results of the questionnaire for further rehabilitation planning. This survey is carried out on the basis of a quantitative short questionnaire with ready-to-use answering options in order to allow the highest possible return rate within the daily routine of a working day of a specialist.

Overall, the pilot study will be designed to deliver a total of 150 responses (100 questionnaires from adolescents in the clinical context and 50 from adolescents without disabilities or chronic diseases). Therefore, 250 questionnaires will be disseminated. The response rate among therapists is expected to be lower. Approximately 125 sheets will be disseminated in order to receive 50 responses from the SPC and rehabilitation clinics. According to relevant literature, this sample size is appropriate for a pilot study and can also provide insights in the psychometric testing. ${ }^{4-51}$

By using the data from the pilot study, various subscales are ascertained by exploratory factor analysis. Cronbach's $\alpha$ is calculated for the different scales as a reliability parameter. The validation testing includes content validity, discriminatory validity and primary construct validity approaches. However, it should be noted that the validity check should be promoted with further assignments and systematic evaluations.

\section{Ethics and dissemination}

The study will be conducted in accordance to the principles of the Helsinki Declaration (Fortaleza 2013) and the standards of good scientific practice. All participants will be informed about the meaning, purpose and procedure of the study as well as the handling of the collected data. Written informed consent will be obtained by our research associates from all participants prior to taking part in the study. The participation in the surveys is voluntary and can be withdrawn at any time. In this case, already collected data will be deleted. Non-participation remains without any consequences. All personal identifiers will be pseudonymised. The study is devoted to the development of a participation measurement instrument for adolescents, one of the most urgent care requirements in social paediatrics and rehabilitation. The study will present findings from the point of view of adolescents, their legal guardians and experts on the theoretical foundation of the concept of participation and the demarcation from the concept of activities, and compose a draft for a new participation assessment instrument in German language, which will be piloted and psychometrically tested. The results can be used for further research and development processes and for the practice of rehabilitation planning. With the knowledge about the theoretical foundation 
of the participation concept, the present model of the ICF-CY can be extended or concretised.

Acknowledgements We acknowledge the financial support within the funding programme Open Access Publishing by the German Research Foundation (DFG). We would like to thank the participants of our first study on social participation (Fink et al 2016), with the help of which we were able to determine the great need for the development of a new assessment instrument.

Contributors TB wrote the initial draft of this manuscript. BG and AF led the grant application, and AF wrote the study protocol for the Ethics Review Committee. $\mathrm{LH}, \mathrm{OM}, \mathrm{ALN}$ and JR assisted in the grant application. All authors have read and approved the final version of this manuscript.

Funding This study is supported by the German Research Foundation grant number 404636197 (contact via www.dfg.de).

Competing interests None declared.

Patient consent for publication Not required.

Ethics approval The Ethics Review Committee at the Martin-Luther-University Halle-Wittenberg granted approval.

Provenance and peer review Not commissioned; peer reviewed for ethical and funding approval prior to submission.

Data sharing statement The main data of this study come from interviews with young people who need special protection. The ethic vote does not allow sharing of the data.

Open access This is an open access article distributed in accordance with the Creative Commons Attribution Non Commercial (CC BY-NC 4.0) license, which permits others to distribute, remix, adapt, build upon this work non-commercially, and license their derivative works on different terms, provided the original work is properly cited, appropriate credit is given, any changes made indicated, and the use is non-commercial. See: http://creativecommons.org/licenses/by-nc/4.0/.

\section{REFERENCES}

1. World Health Organization. International classification of functioning, disability and health. Geneva: ICF, 2001:339.

2. Rohrmann E, Teilhabe WE, Wacker E. Wir wollen mehr als nur dabei sein. Marburg: Lebenshilfe-Verl, 2005:261-72.

3. Stucki G, Cieza A, Melvin J. The International Classification of Functioning, Disability and Health (ICF): a unifying model for the conceptual description of the rehabilitation strategy. J Rehabil Med 2007;39:279-85.

4. Whiteneck G, Dijkers MP. Difficult to measure constructs: conceptual and methodological issues concerning participation and environmental factors. Arch Phys Med Rehabil 2009;90(11 Suppl):S22-35.

5. Adair B, Ullenhag A, Keen D, et al. The effect of interventions aimed at improving participation outcomes for children with disabilities: a systematic review. Dev Med Child Neurol 2015;57:1093-104.

6. van Vulpen LF, de Groot S, Rameckers EA, et al. Improved parentreported mobility and achievement of individual goals on activity and participation level after functional power-training in young children with cerebral palsy: a double-baseline controlled trial. Eur J Phys Rehabil Med 2018:54:730-7.

7. Willis C, Girdler S, Thompson M, et al. Elements contributing to meaningful participation for children and youth with disabilities: a scoping review. Disabil Rehabil 2017;39:1771-84.

8. Raghavendra P. Participation of children with disabilities: measuring subjective and objective outcomes. Child Care Health Dev 2013;39:461-5

9. Granlund M. Participation--challenges in conceptualization, measurement and intervention. Child Care Health Dev 2013;39:470-3.

10. King G. Perspectives on measuring participation: going forward. Child Care Health Dev 2013;39:466-9.

11. King G, McDougall J, Dewit D, et al. Predictors of change over time in the activity participation of children and youth with physical disabilities. Child Health Care 2009;38:321-51.

12. Sahlin KB, Lexell J. Impact of organized sports on activity, participation, and quality of life in people with neurologic disabilities. Pm R 2015;7:1081-8.

13. Powrie B, Kolehmainen N, Turpin M, et al. The meaning of leisure for children and young people with physical disabilities: a systematic evidence synthesis. Dev Med Child Neurol 2015;57:993-1010.
14. Gebhard B, Fink A. [Measuring participation - discussion of the theoretical foundations of current assessment instruments]. Klin Padiatr 2015;227:251-8.

15. World Health Organization. International classification of functioning, disability and health: Children and youth version: ICF-CY: World Health Organization, 2007

16. Chiarello LA, Palisano RJ, Orlin MN, et al. Understanding participation of preschool-age children with cerebral palsy. J Early Interv 2012;34:3-19.

17. Chien CW, Rodger S, Copley J, et al. Comparative content review of children's participation measures using the International Classification of Functioning, Disability and Health-Children and Youth. Arch Phys Med Rehabil 2014;95:141-52.

18. Imms $\mathrm{C}$, Granlund $\mathrm{M}$, Wilson $\mathrm{PH}$, et al. Participation, both a means and an end: a conceptual analysis of processes and outcomes in childhood disability. Dev Med Child Neurol 2017;59:16-25.

19. McConachie H, Colver AF, Forsyth RJ, et al. Participation of disabled children: how should it be characterised and measured? Disabil Rehabil 2006;28:1157-64.

20. Adolfsson M, Malmqvist J, Pless M, et al. Identifying child functioning from an ICF-CY perspective: everyday life situations explored in measures of participation. Disabil Rehabil 2011;33(1314):1230-44.

21. Coster W, Khetani MA. Measuring participation of children with disabilities: issues and challenges. Disabil Rehabil 2008;30:639-48.

22. Hollenweger J, Kraus de Camargo OA. ICF-CY: Internationale Klassifikation der Funktionsfähigkeit, Behinderung und Gesundheit bei Kindern und Jugendlichen. 1st edn. Bern: Huber, 2012.

23. Schuntermann MF. 10 Jahre ICF - Erfahrungen und Probleme. Hallesche Beiträge zu den Gesundheits- und Pflegewissenschaften 2011:10:1-7

24. Granlund M, Arvidsson P, Niia A, et al. Differentiating activity and participation of children and youth with disability in Sweden. Am J Phys Med Rehabil 2012;91(13 Suppl 1):S84-96.

25. Maxwell G, Augustine L, Granlund M. Does thinking and doing the same thing amount to involved participation? Empirical explorations for finding a measure of intensity for a third ICF-CY qualifier. Dev Neurorehabil 2012;15:274-83.

26. Imms C, Adair B, Keen D, et al. 'Participation': a systematic review of language, definitions, and constructs used in intervention research with children with disabilities. Dev Med Child Neurol 2015;57:29-38.

27. Field DA, Miller WC, Ryan SE, et al. Measuring participation for children and youth with power mobility needs: a systematic review of potential health measurement tools. Arch Phys Med Rehabil 2016;97:462-77.

28. Phillips RL, Olds T, Boshoff K, et al. Measuring activity and participation in children and adolescents with disabilities: a literature review of available instruments. Aust Occup Ther J 2013;60:288-300.

29. Rainey L, van Nispen R, van der Zee C, et al. Measurement properties of questionnaires assessing participation in children and adolescents with a disability: a systematic review. Qual Life Res 2014:23:2793-808

30. Voll R. Social participation and vocational integration as an objective of child and adolescent psychiatric rehabilitation]. Z Kinder Jugendpsychiatr Psychother 2009;34:421-9.

31. Fink A, Gebhard B, Erdwiens S, et al. Reliability of the German version of the Children's Assessment of Participation and Enjoyment (CAPE) and Preferences for Activities of Children (PAC). Child Care Health Dev 2016;42:683-91.

32. Urschitz M, Gebhard B, Philippi H. Partizipation und Bildung als Endpunkte in der pädiatrischen Versorgungsforschung. Zeitschrift Kinder- und Jugendmedizin 2016;16:206-17.

33. Coster W, Bedell G, Law M, et al. Psychometric evaluation of the participation and environment measure for children and youth. Dev Med Child Neurol 2011:53:1030-7.

34. Bedell G. Further validation of the Child and Adolescent Scale of Participation (CASP). Dev Neurorehabil 2009;12:342-51.

35. King GA. CAPE/PAC manual: Children's assessment of participation and enjoyment \& preferences for activities of children. San Antonio, TX: PsychCorp, 2004

36. Brentel H. Soziale Rationalität: Entwicklungen, Gehalte und Perspektiven von Rationalitätskonzepten in den Sozialwissenschaften. Wiesbaden: Springer, 1999

37. Glaser BG, Strauss AL. The discovery of grounded theory: strategies for qualitative research. New York; New Brunswick (USA: Aldine Transaction, 1999

38. Mason M. Sample Size and Saturation in PhD Studies Using Qualitative Interviews. Forum: Qualitative Social Research 2010:11.

39. Lewis J, Turley C. In: Ritchie J, Lewis J, McNaughton Nicholls C, Qualitative research practice: a guide for social science students and researchers. 2st edn. London: Sage Publications Ltd, 2014. 
40. Yeo A, Legard R, Keegan J, et al. In-Depth Interviews. In: Ritchie J, Lewis J, McNaughton Nicholls C, eds. Qualitative research practice: a guide for social science students and researchers. 2nd edn. London: Sage Publications Ltd, 2014:177-210.

41. Heinzel F. Qualitative Interviews mit Kindern. In: Friebertshäuser $\mathrm{B}$, ed. Handbuch qualitative Forschungsmethoden in der Erziehungswissenschaft. Juventa, 2003:306-413.

42. Zill N. Advantages and limitations of using children and adolescents as survey respondents. In: Cynamon ML, Kulka RA, eds. Seventh Conference on Health Survey Research Methods: US Department of Health and Human Services, 2001:47-50.

43. Arthur S, Mitchell M, Lewis J, et al. Designing Fieldwork. In: Ritchie J, Lewis J, McNaughton Nicholls C, eds. Qualitative research practice: a guide for social science students and researchers. 2nd edn. London: Sage Publications Ltd, 2014:147-76.

44. Freitas $\mathrm{H}$, Oliveira M, Jenkins $\mathrm{M}$, et al. The Focus Group, a qualitative research method. 1998;1:1-22.
45. Nassar-McMillan SC, Borders LD. Use of focus groups in survey item development. The Qualitative Report 2002;7:1-12.

46. Boyatzis R. Transforming qualitative information: thematic analysis and code development. Thousand Oaks, CA: Sage, 1998.

47. Lenzner T, Neuert C, Otto W, et al. GESIS Survey Guideline. Mannheim, Germany: GESIS - Leibnitz Institute for the Social Sciences, 2016.

48. Simpson DD. A conceptual framework for transferring research to practice. J Subst Abuse Treat 2002;22:171-82.

49. Browne RH. On the use of a pilot sample for sample size determination. Stat Med 1995;14:1933-40.

50. Lancaster GA, Dodd S, Williamson PR. Design and analysis of pilot studies: recommendations for good practice. J Eval Clin Pract 2004;10:307-12.

51. MacCallum RC, Widaman KF, Preacher KJ, et al. Sample size in factor analysis: the role of model error. Multivariate Behav Res 2001;36:611-37. 